\title{
Motivational influences on word recognition: IV. Cortical magnification does not explain parafoveal versus foveal differences
}

\author{
EVA DREIKURS FERGUSON \\ Southern Illinois University, Edwardsville, Illinois
}

\begin{abstract}
In two experiments, hungry and satiated subjects were compared on word recognition for words of three types of content: food, positively emotional, or negatively emotional content. The purpose was to assess whether expanding the size of the parafoveal image would yield patterns of word processing that were similar to those obtained under foveal viewing. Words of 17-mm size were created to take cortical magnification into account. The conditions in Experiment 1 yielded overall high levels of performance, and the conditions in Experiment 2 yielded overall low levels of performance; yet, the usual foveal patterns of word recognition failed to be evident, especially with respect to motivation. In Experiment 2, highly frequent words were significantly more easily recognized than were infrequent words, but the usual facilitation of hunger (as opposed to satiation) was absent for both experiments. The data suggest that foveal and parafoveal viewing lead to two quite distinct forms of lexical processing.
\end{abstract}

In prior studies by Ferguson (Erwin \& Ferguson, 1979; Ferguson, 1983, 1988, 1989, 1992), with the use of an "information purchasing"' procedure, it was found that word recognition under foveal but not under parafoveal viewing was facilitated by hunger as opposed to satiation. That is, under foveal viewing, hungry subjects required fewer presentations (less information purchase) before correctly recognizing very briefly projected words. Under parafoveal viewing, not only were hungry subjects found not to show the significant facilitation, but, under some circumstances (Ferguson, 1989), the satiated subjects actually performed (nonsignificantly) better than the hungry subjects. In a number of additional ways, parafoveal word recognition did not follow the norm found for foveal processing. For example, low word frequency was found consistently to impair performance under foveal viewing, but under parafoveal viewing, low-frequency words were not necessarily recognized with greater difficulty than were words of high frequency. In a recent study, Ferguson (1992) sought to identify whether the source of these functional foveal-parafoveal processing differences was the fact that under parafoveal processing only one cerebral hemisphere initially encodes a given stimulus, whereas under foveal viewing, both hemispheres initially encode the stimulus. When conditions permitted the parafoveally viewed stimulus to be initially encoded concurrently by both hemispheres, parafoveal processing more closely resembled foveal processing, but differences were still evident between the two types of word recognition.

Correspondence should be sent to E. D. Ferguson, Box 1121, Psychology Department, Southern Illinois University, Edwardsville, IL 62026.
Although the question of one or two hemispheres initially encoding the stimulus was found not to be the major factor to account for the differences between parafoveal and foveal processing, an additional variable needed to be examined, that of cortical magnification. For some time, it has been known (Rovamo \& Virsu, 1979; Tootell, Silverman, Switkes, \& De Valois, 1982) that the area of cortex stimulated by a foveal input is much larger than that which is stimulated by input obtained parafoveally or more peripherally. Assessment of the visual field representation in the human striate cortex (Horton \& Hoyt, 1991) confirms earlier estimates. In Ferguson's (1988, $1989,1992)$ studies, the stimuli were of equal size for both foveal and parafoveal viewing, as is the custom in typical studies of reading that compare foveal with parafoveal viewing (e.g., Balota \& Rayner, 1991). However, to stimulate an equivalent amount of cortical area, the parafoveal words need to be enlarged.

This issue was addressed in the present investigation. The question asked was whether the difference in the pattern of processing between foveal and parafoveal words was mainly due to the amount of cortex stimulated. If so, one would expect parafoveal word recognition to be similar to foveal processing if the parafoveal word size was expanded (cortical magnification). By similar, it is meant that hunger, in comparison with satiation, would facilitate recognition, and that word frequency and emotional word content would lead to some words (high vs. low frequency, and positively vs. negatively emotional) being recognized more readily than others. However, if the way in which words are processed is inherently different for parafoveal than for foveal viewing, word recognition patterns should not be comparable even with cortical magnification. 
To magnify the input and still permit the words to fall within the parafoveal region (between $2^{\circ}$ and $6^{\circ}$ of center fixation), $17-\mathrm{mm}$ words were utilized; this is approximately double the size of the words used in the earlier foveal studies with the same apparatus (Ferguson 1988, 1989, 1992).

\section{EXPERIMENTS 1 AND 2}

\section{Method}

Subjects. Each experiment had 16 hungry and 16 satiated subjects. In each of the two experiments, 16 men and 16 women undergraduate volunteers were randomly assigned either to refrain from eating for $12 \mathrm{~h}$ before testing or to eat a big meal within $1 \mathrm{~h}$ prior to testing. Righthanded subjects with 20/20 or corrected-to-normal vision were tested at the students' usual lunch time. The same words and the same general procedure were used in both experiments. However, Experiment 1 was conducted under easy test conditions that led to what appeared to be a ceiling effect. Because failure to reveal the normative foveal pattern could have been due to that fact, Experiment 2 was conducted with more difficult test conditions. This permitted a wider performance range and thus provided a fairer test of the question of to what extent parafoveal processing is similar to or different from foveal processing under conditions of cortical magnification.

Apparatus. A Gerbrands three-field tachistoscope, a Gerbrands lamp drive circuit unit, and a Gerbrands digital integrated circuit unit were used, as described more fully previously (Ferguson, 1988). A Gerbrands logic unit controlled which of three fields was activated. A central-fixation " $X$ " was visible before and after word exposure, and catch trials were used to assure center fixation. Luminosity was $5.65 \mathrm{~mL}$ in all fields in Experiment 1, and it was $1.00 \mathrm{~mL}$ in Experiment 2.

Procedure. The overall procedure followed that described previously (Ferguson, 1988), with two words repeated in random alternation to the left or right of center until correctly recognized on two consecutive presentations for the given word. When a word in one visual field was recognized to criterion (two consecutive correct recognitions), a new word appeared in that field, regardless of what occurred in the other field. A given field contained six words, two per category, with the visual angle of all words between $2^{\circ}$ and $6^{\circ}$ from center fixation.

The words, previously rated for affective content, represented three categories. High and low frequencies were measured according to Thorndike and Lorge's (1944) norms, as well as interletter associativeness of generated value (Underwood \& Schulz, 1960). One high- and one low-frequency word per category occurred in each field. Across subjects, word order and left versus right field of presentation were counterbalanced. Within each experiment, the subjects were randomly assigned to one of two word lists. The food words in one list were jam, gel, rib, and oat, and in the other list, they were bun, pie, sip, and tea. The positively emotional words in one list were toy, cub, sex, and gem, and in the other list, they were wit, hug, fun, and pal. The negatively emotional words in one list were hex, mud, jab, and cry, and in the other list, they were $f l u, s i n$, woe, and rat.

The 17-mm words, in black lettering, fit the parafoveal space and were created by photocopying in double size the letters used in prior foveal studies. Word duration was $8 \mathrm{msec}$ in Experiment 1 and $5 \mathrm{msec}$ in Experiment 2.

Overall, the previous parafoveal procedure was used. No corrective feedback occurred until the subject correctly identified the word on 2 consecutive presentations, and after 29 presentations, the word exposure was systematically increased. To permit assessment of information purchasing within each study over a constant stimulus duration, and to permit comparison with data from prior studies (Erwin \& Ferguson, 1979; Ferguson, 1983, 1988, 1989, 1992), data from the present investigation are presented as trials to first correct recognition and not as trials to criterion.

\section{Results and Discussion}

For Experiment 1, none of the main effects normally obtained with foveal viewing were found. As is evident in Table 1, which presents the pooled data for the two word lists, even with cortical magnification the parafoveal pattern does not resemble foveal word processing. Neither word frequency nor word category was significant, and motivation was not facilitative. Although two $2 \times 2$ interactions were significant-those of category $\times$ frequency $[F(2,60)=7.30, p=.001]$ and visual field $\times$ category $[F(2,60)=3.39, p=.04]$-there was no clear-cut pattern. Motivation had minimal effect, and that was (nonsignificantly) in the direction opposite to what would be predicted for foveal viewing: the mean number of presentations to first correct recognition was slightly positively correlated with subjective hunger ratings (on a scale from 1 to 7), and slightly more presentations were required for the hungry than for the satiated subjects.

Because of the overall good performance in Experiment 1 , the ceiling effect could have prevented the pattern to appear that is characteristic of foveal processing. However, as is evident in Table 2, Experiment 2 did not conclusively support a foveal pattern either, in spite of the wider performance range. The most striking finding was the significant word frequency effect $[F(1,30)=7.19$, $p=.012]$, which was in the usual (i.e., foveal) direction of high-frequency words being recognized sooner. The category $\times$ frequency interaction was again significant $[F(2,60)=12.74, p<.001]$. The nonfacilitation of hunger motivation was even more evident in Experiment 2 than in Experiment 1. Subjective hunger ratings correlated +.188 with the number of presentations required for first correct recognition, and mean number of presentations was (nonsignificantly) higher for hungry than for satiated subjects: Satiated subjects required an average of 9.89 presentations, whereas hungry subjects

Table 1

Mean Number of Presentations to First Correct Recognition, Experiment 1

\begin{tabular}{|c|c|c|c|c|c|c|}
\hline \multirow{2}{*}{$\begin{array}{c}\text { Word } \\
\text { Frequency }\end{array}$} & \multicolumn{3}{|c|}{ Hungry } & \multicolumn{3}{|c|}{ Satiated } \\
\hline & Food & Positive & Negative & Food & Positive & Negative \\
\hline \multicolumn{7}{|c|}{ Left Visual Field } \\
\hline Low & 2.69 & 6.06 & 10.88 & 1.94 & 2.56 & 5.19 \\
\hline High & 3.69 & 1.25 & 2.75 & 7.38 & 1.38 & 4.88 \\
\hline \multicolumn{7}{|c|}{ Right Visual Field } \\
\hline Low & 3.50 & 5.25 & 2.13 & 2.25 & 6.81 & 3.25 \\
\hline High & 4.06 & 1.38 & 2.38 & 2.69 & 1.19 & 3.81 \\
\hline
\end{tabular}


Table 2

Mean Number of Presentations to First Correct Recognition, Experiment 2

\begin{tabular}{|c|c|c|c|c|c|c|}
\hline \multirow{2}{*}{$\begin{array}{l}\text { Word } \\
\text { Frequency }\end{array}$} & \multicolumn{3}{|c|}{ Hungry } & \multicolumn{3}{|c|}{ Satiated } \\
\hline & Food & Positive & Negative & Food & Positive & Negative \\
\hline \multicolumn{7}{|c|}{ Left Visual Field } \\
\hline $\begin{array}{l}\text { Low } \\
\text { High }\end{array}$ & $\begin{array}{l}10.69 \\
12.38\end{array}$ & $\begin{array}{l}8.69 \\
5.88\end{array}$ & $\begin{array}{l}17.12 \\
10.06\end{array}$ & $\begin{array}{r}5.44 \\
14.13\end{array}$ & $\begin{array}{r}14.12 \\
5.26\end{array}$ & $\begin{array}{r}17.31 \\
7.31\end{array}$ \\
\hline \multicolumn{7}{|c|}{ Right Visual Field } \\
\hline $\begin{array}{l}\text { Low } \\
\text { High }\end{array}$ & $\begin{array}{r}13.76 \\
9.81\end{array}$ & $\begin{array}{r}17.56 \\
7.94\end{array}$ & $\begin{array}{l}11.56 \\
12.32\end{array}$ & $\begin{array}{r}5.82 \\
10.50\end{array}$ & $\begin{array}{r}15.26 \\
5.50\end{array}$ & $\begin{array}{l}9.06 \\
9.00\end{array}$ \\
\hline
\end{tabular}

Note $-N=32$ subjects. Word height, $17 \mathrm{~mm}$. Word duration, $5 \mathrm{msec}$. Luminosity, $1.00 \mathrm{~mL}$.

required an average of 11.48 presentations, before correct word recognition. Although satiation was not significantly more effective for parafoveal word processing, the reversal of effects is significant. That is, under foveal viewing, the subjective ratings of hunger consistently correlated negatively with the amount of information required before recognition, and the hungry subjects consistently recognized words with fewer presentations than did the satiated subjects.

In summary, it is clear that although magnification of the parafoveal image can produce some of the "normal" word processing effects (e.g., words of high frequency are recognized more readily than words of low frequency), other effects (e.g., those of affective word content) are not necessarily evident. Moreover, rather than facilitate parafoveal word processing, motivation seems to harm it. When increased arousal or effort is counterproductive, the underlying mechanisms are likely not to be the same as those that are involved when increased arousal or effort improves performance. Within Hullian theory, Spence (Spence, Farber, \& McFann, 1956) and Taylor (1956) posited that under heightened response interference, increased motivation would impair performance. In more recent writings, Norman and Bobrow (1975) pointed out that increased effort would not improve performance under conditions of high data limitation.

From a viewpoint that conceptualizes learning and memory in terms of neural circuitry like cell assemblies (Martinez, Schulteis, \& Weinberger, 1991), depending on the neural pathways, an increase in arousal or effort can either facilitate or impair performance. It may be that when circuits are well established for specific functions (which for the present task would involve, e.g., memory retrieval of a word representation, and making a match between the representation of the retrieved word and bits of incoming information), arousal or effort can make the function faster or more efficient. However, if the circuitry is not well established, many wrong searches may be attempted, which slows down the recognition process. This hypothesis needs further investigation. Nevertheless, the possibility remains that parafoveal word processing is in some fundamental ways not like foveal word processing. This might be because of hard-wired differences between foveal and parafoveal pathways. It also could be the result of many years of selective practice, in which extraction of meaningfulness from stimuli was diverted primarily to foveal input, thereby leading to different memory search and matching strategies for foveal as opposed to parafoveal processing of lexical information.

\section{REFERENCES}

BAlotA, D. A., \& RAYNER, K. (1991). Word recognition processes in foveal and parafoveal vision. In D. Besner \& G. Humphreys (Eds.), Basic processes in reading: Visual word recognition (pp. 198-232). Hillsdale, NJ: Erlbaum.

ERWIN, R. J., \& FERGUSON, E. D. (1979). The effect of food and water deprivation and satiation on recognition. American Journal of Psychology, 92, 611-626.

Ferguson, E. D. (1983). The effect of motivation and word characteristics on recognition. American Journal of Psychology, 96, 253-266.

FERGusOn, E. D. (1988). Motivational influences on word recognition: I. Foveal and parafoveal viewing. Bulletin of the Psychonomic Society, 26, 203-205.

Ferguson, E. D. (1989). Motivational influences on word recognition: II. Affective coding. Bulletin of the Psychonomic Society, 27, 307-310.

FERGUSON, E. D. (1992). Motivational influences on word recognition: III. Parafoveal processing differs from foveal processing. Bulletin of the Psychonomic Society, 30, 47-50.

Horton, J. C., \& HoYT, W. F. (1991). The representation of the visual field in human striate cortex. Archives of Ophthalmology, 109, 816-824.

Martinez, J. L., Jr., Schulteis, G., \& Weinberger, S. B. (1991). How to increase and decrease the strength of memory traces: The effects of drugs and hormones. In J. L. Martinez, Jr., \& R. P. Kesner (Eds.), Learning and memory: A biological view (2nd ed., pp. 149198). San Diego: Academic Press.

Norman, D. A., \& Bobrow, D. G. (1975). On data-limited and resourcelimited processes. Cognitive Psychology, 7, 44-64.

Rovamo, J., \& VIRSU, V. (1979). An estimation and application of the human cortical magnification factor. Experimental Brain Research, 37, 495-510.

SPENCE, K. W., Farber, E. E., \& McFanN, H. H. (1956). The relation of anxiety (drive) level to performance in competitional and noncompetitional paired-associates learning. Journal of Experimental Psychology, 52, 296-305.

TAYLOR, J. A. (1956). Drive theory and manifest anxiety. Psychological Bulletin, 53, 303-320.

THORNDIKE, E. E., \& LORGE, I. (1944). The teacher's book of 30,000 words. New York: Teachers College Press, Columbia University.

Tootell, R. B. H., Silverman, M. S., Switkes, E., \& De Valois, R. L. (1982). Deoxyglucose analysis of retinotopic organization in primate striate cortex. Science, 218, 902-904.

UNDERWOOD, B. J., \& SCHULZ, R. W. (1960). Meaningfulness and verbal learning. Philadelphia: Lippincott.

(Manuscript received July 1, 1993.) 